\title{
ANALISIS PROFITABILITAS USAHATANI TEBU (Saccharum officinarum, L) DI KECAMATAN BENDAHARA KABUPATEN ACEH TAMIANG
}

\author{
Oleh \\ Walyupin $^{1}$, Muhammad Jamil ${ }^{2}$ dan Cut Gustiana ${ }^{2}$ \\ ${ }^{1}$ Mahasiswa Program Studi Agribisnis Fakultas Pertanian Universitas Samudra \\ ${ }^{2}$ Dosen Fakultas Pertanian Universitas Samudra \\ Penulis dapat dihubungi di email : milcareca@gmail.com atau Hp. 085261361567
}

\begin{abstract}
Abstrak
Tujuan penelitian untuk mengetahui tingkat pendapatan yang di peroleh petani tebu (Saccharum officinarum, L) Di Kecamatan Bendahara Kabupaten Aceh Tamiang. Lokasi penelitian dilakukan di Kecamatan Bendahara Kabupaten Aceh Tamiang. Penelitian ini menggunakan metode survei. Objek penelitian adalah petani tebu saja yang berada di desadesa sampel di Kecamatan Bendahara Kabupaten Aceh Tamiang. Penelitian ini dilaksanakan pada Bulan Januari sampai April 2018. Sampel petani tebu di daerah penelitian sebanyak 32 orang .
\end{abstract}

Hasil penelitian: Karakteristik petani sampel di Kecamatan Bendahara yaitu: umur rata-rata petani sampel adalah 41,1 tahun, tingkat pendidikan rata-rata adalah 10,4 tahun, rata-rata pengalaman berusahatani 12,6 tahun dan jumlah tanggungan keluarga petani ratarata 4 orang.

Dari hasil penelitian ini di perolehlah BEP (Break Even Point) Usahatani tebu di Kecamatan Bendahara Kabupaten Aceh Tamiang harus berproduksi sebesar 408 m/MT dengan total penerimaan sebesar Rp 831. 363 /MT, Analisis profitabilitasnya nilai yang di peroleh NPM (Net Profit Margin) sebesar 69\% yang menunjukan bahwa penjualan relatif lebih tinggi $69 \%$ dari pada pengeluaran dan ROI (Return On Invesment) $230 \%$ yang artinya setiap pengeluaran Rp 1-, maka mendapatkan keuntungan sebesar Rp 2,30 atau 230\% dibandingkan dengan biaya pengeluaran.

Kata kunci: Profitabilitas, Usahatani Tebu, Break Even Point (BEP), Net Profit Margin (NPM), Return On Invesment (ROI)

\section{PENDAHULUAN \\ Latar Belakang}

Indonesia dikenal sebagai negara yang memiliki kesuburan tanah yang sangat cocok untuk melakukan kegiatan pertanian. Hal ini menjadikan alasan dasar bagi negara-negara luar yang menjajah Indonesia pada masa lampau yang digunakan untuk mengambil hasil pertanian yang ada di bumi Pertiwi ini. Pertanian memiliki peranan yang sangat penting bagi negara Indonesia dikarenakan pertanian menjadi salah satu penyokong perekonomian Indonesia, pada saat sekarang ini sektor pertanian memegang peranan penting dalam struktur ekonomi nasional, dikarenakan terbukti sektor pertanian lebih tahan dalam menghadapi kirisis ekonomi dibandingkan dengan sektor-sektor lainnya.

Krisis ekonomi yang diakibatkan krisis moneter serta bencana alam yang terus menerus telah ikut mempengaruhi perekonomian Indonesia baik secara makro maupun mikro. Krisis ini menyebabkan sektor indusrti dan jasa mengalami penurunan yang cukup tajam. Namun dipihak lain justru sektor pertanian masih tetap eksis. Hal ini berarti bahwa perekonomian Indonesia tidak dapat sepenuhnya tergantung pada sektor industri dan jasa saja, tetapi juga harus tergantung dari sektor pertanian. (Soekartawi, 2000:13).

Selain itu sektor pertanian memiliki peran dalam mencukupi kebutuhan penduduk,meningkatkan pendapatan petani,penyediaan bahan baku industri, memberi peluang usaha serta kesempatan kerja dan menunjang untuk ketahanan nasional. Salah satu subsektor pertanian yaitu perkebunandalam hal ini subsektor perkebunan diklasifikasikan menjadi dua kelompok yaitu tanaman musiman dan tanaman tahunan. Tanaman musiman merupakan tanaman yang hanya bisa berproduksi satu kali dalam siklus 
hidup tanaman tersebut, misalnya tebu, nanas, tembakau dan lain sebagainya. Sementara itu tanaman tahunan membutuhkan waktu yang lebih panjang untuk berproduksi bahkan dapat memakan waktu lima tahun lebih tetapi tanaman ini dapat dipanen berkali-kali dalam siklus hidupnya.

Tebu dalam bahasa inggris disebut sugar cane merupakan tanaman yang unik bentuknya dan cara mekonsumsinya, tebu merupakan tanaman yang berbentuk panjang yang penanamannya bisa dilakukan dengan mata tunas. Tanaman tebu juga sering kita jumpai pada masyarakat luar untuk bahan baku pembuatan gula. Tanaman ini hanya dapat tumbuh di daerah yang beriklim tropis contohnya seperti negara Indonesia. Tebu termasuk dalam jenis tanaman rumputrumputan, sampai saat ini tanaman tebu terus dibudidayakan sebagai bahan baku utama dalam pembuatan gula pasir, yang banyak digunakan untuk konsumsi rumah tangga maupun industri olahan oleh masyarakat Indonesia.

Tebu yang dibudidayakan oleh petani diharapkan memiki tingkat keuntungan yang maksimal bagi petani, karena disamping memberikan pendapatan kepada petani pengelola sekaligus petani dapat membuka lapangan kerja kepada diri petani dan keluarga, serta kepada masyarakat sekitarnya. Pendapatan yang diperoleh petani diharapkan dapat menjamin petani untuk melangsungkan kegiatan usahatani terutama kalau tebu untuk membiayai berbagai keperluan seperti biaya pemupukan dan lainnya.

\section{Identifikasi Masalah}

Apakah usahatani tanaman tebu(Saccharum officinarum, L) di Kecamatan Bendahara Kabupaten Aceh Tamiang menguntungkan?

\section{Tujuan Penelitian}

Tujuan dari penelitian ini untuk menganalisis tingkat keuntungan (profitabilitas) usahatani tebu(Saccharum officinarum, L) di Kecamatan Bendahara Kabupaten Aceh Tamiang.

\section{Hipotesis Penelitian}

Usahatani tanaman tebu (Saccharum officinarum L) di Kecamatan Bendahara
Kabupaten Aceh Tamiang menguntungkan apabila ditinjau dari profitabilitasnya.

\section{METODOLOGI PENELITIAN Lokasi, Objek dan Ruang Lingkup dan Waktu Penelitian}

Metode penelitian yang digunakan dalam penelitian ini adalah metode survey. Menurut Nazir (2005:56) "Metode survei adalah penyelidikan untuk memperoleh fakta dari gejala-gejala dan mencari keteranganketerangan secara faktual, baik tentang intitusi sosial, ekonomi maupun politik dari suatu kelompok atau dari suatu daerah". Lokasi penelitian yaitu Kecamatan Bendahara Kabupaten Aceh Tamiang, dengan pertimbangan bahwa Kecamatan tersebut terdapat petani yang mengusahakan usahatani tebu. Objek dalam penelitian ini dibatasi hanya pada petani yang melakukan usahatani tebu yang berada di Kecamatan Bendahara. Ruang lingkup penelitian ini yaitu hanya menganalisis profitabilitas usahatani tebu. Waktu penelitian ini telah dilaksanakan pada bulan Januari sampai dengan Maret 2018.

\section{Teknik Penentuan Sampel}

Penentuan desa sampel penelitian yang akan di lakukan yaitu dengan cara Purposive Sampling. Menurut Sugiyono (2008 : 11)"Purposive Sampling adalah teknik penentuan sampel dengan pertimbangan tertentu".

Kecamatan Bendahara terdiri dari 33 desa, dari 33 desa yang ada 4 desa dijadikan sampel, dengan pertimbangan bahwa desa tersebut memiliki usahatani tebu yang lahannya luas dibandingkan desa lainnya, adapun desa tersebut yaitu desa Marlempang, Bandar Khalifah, Raja, dan Mesjid Sungai Iyu.

Pengambilan sampel dilakukan dengan cara menggunakan metode sampling jenuh atau sensus. Pengertian dari sampling jenuh menurut Sugiyono (2008: 78) "Sampling jenuh atau sensus adalah teknik penentuan sampel bila semua anggota populasi dijadikan sampel istilah lain sampling jenuh adalah sensus".

Berdasarkan pengertian tersebut, maka dapat kita ketahui bahwa sampling jenuh atau sensus adalah teknik penentuan sampel dari semua anggota populasi, dalam penelitian ini karena jumlah populasinya terbatas (tidak terlalu banyak) sehingga seluruh populasinya dijadikan sampel penelitian, sebagai berikut: 
Tabel 3. Jumlah Populasi dan Jumlah Sampel Pada Usahatani Tebu di Kecamatan Bendahara Kabupaten Aceh Tamiang, 2018

\begin{tabular}{|c|l|c|c|}
\hline No & \multicolumn{1}{|c|}{ Desa Sampel } & $\begin{array}{c}\text { Populasi } \\
\text { ( orang })\end{array}$ & $\begin{array}{c}\text { Sampel } \\
\text { ( orang ) }\end{array}$ \\
\hline 1 & Marlempang & 6 & 6 \\
2 & Badar Khalifah & 11 & 11 \\
3 & Raja & 7 & 7 \\
4 & Mesjid Sungai Iyu & 8 & 8 \\
\hline \multicolumn{2}{|c|}{ Jumlah } & 32 & 32 \\
\hline
\end{tabular}

Sumber : Data Primer, 2018 (diolah)

Dari tabel 3 di atas dapat dilihat bahwa jumlah populasi dalam penelitian ini sama dengan jumlah sampel yaitu Desa Marlempang 6 orang, Bandar Khalifah 11 orang, Raja 7 orang dan Masjid Sungai Iyu 8 orang.

\section{Model Analisis dan Pengujian Hipotesis}

Data yang diperoleh di lapangan kemudian diolah dengan cara di tabulasikan menurut keperluan analisis. Model yang digunakan dalam penelitian ini adalah dengan menggunakan analisis profitabilitas sebagai berikut :

Net Profit Margin (NPM) dengan rumus :

$\mathrm{NPM}=\frac{\text { Keuntungan }}{\text { Penjualan }} \times 100 \%$....(Agus R

Sartono, 2008: 123)

Dimana :

Keuntungan : selisih nilai produksi dengan total biaya produksi

Penjualan : Jumlah nilai produksi yang dihasilkan (Rp)

Jika Net Profit Margin> 5\% Maka terima $\mathrm{H}_{\mathrm{a}}$ tolak $\mathrm{H}_{\mathrm{o}}$

Jika Net Profi Margin< 5\% Maka terima $\mathrm{H}_{\mathrm{o}}$ tolak $\mathrm{H}_{\mathrm{a}}$

Keterangan :

$\mathrm{H}_{\mathrm{a}}$ : Net Profit Margin meningkat maka laba yang diperoleh semakin tinggi

$\mathrm{H}_{\mathrm{O}} \quad$ : Net Profit Margin menurun dan laba yang diperoleh semakin rendah

\section{Return Of Investment (ROI) dengan rumus} :

ROI $=\frac{\text { Keuntungan }}{\text { Biaya } \text { Produksi }} \times 100 \%$....(Iman

Seoharto, $2001: 95$ )

Dimana :

Keuntungan : Selisih nilai produksi dengan total biaya produksi

Biaya Produksi : Biaya yang dikeluarkan selama memproduksi.

Jika Rerurn Of Invesment $>50 \%$ maka terima $\mathrm{H}_{\mathrm{a}}$ tolak $\mathrm{H}_{\mathrm{o}}$
Jika Rerurn Of Invesment $<50 \%$ maka terima

$\mathrm{H}_{\mathrm{o}}$ tolak $\mathrm{H}_{\mathrm{a}}$

Keterangan :

$\mathrm{H}_{\mathrm{a}}$ : JikaRerurn Of Invesment (ROI) lebih dari 50\% maka usahatani tebu menguntungkan untuk dilaksanakan.

$\mathrm{H}_{\mathrm{o}} \quad$ Jika Rerurn Of Invesment (ROI) kurang dari 50\% maka usahatani tebu tidak menguntungkan untuk dilaksanakan.

\section{Break Even Point (BEP)}

Break Event Point terbagi dua yaitu BEP dalam Unit dan BEP dalam Rupiah, dapat dihitung dengan rumus sebagai berikut :

BEP dalam Unit $=\frac{\mathrm{TFC}}{\mathrm{P}-\mathrm{AVC}}$

Keterangan :

$\mathrm{TFC}=$ Total Biaya Tetap $(\mathrm{Rp} / \mathrm{Ha} / \mathrm{MT})$.

$\mathrm{P} \quad=\operatorname{Harga}(\mathrm{Rp} / \mathrm{m})$

$\mathrm{AVC}=$ Rata-rata Biaya Variabel

$(\mathrm{Rp} / \mathrm{Ha} / \mathrm{MT})$

BEP dalam Rupiah $=\frac{\mathrm{TFC}}{1-\mathrm{AVC} / \mathrm{P}}$

Keterangan :

TFC = Total BIaya Tetap (Rp/Ha/MT).

$\mathrm{P} \quad=\operatorname{Harga}(\mathrm{Rp} / \mathrm{m})$

AVC $=$ Rata-rata Biaya Variabel (Rp/Ha/MT)

Di mana,

$\mathrm{H}_{\mathrm{a}}=$ Produksi tebu rata-rata berada diatas BEP

$\mathrm{H}_{\mathrm{O}} \quad$ = Produksi tebu rata-rata berada dibawah BEP

Keterangan :

Jika produksi tebu rata-rata > BEP maka terima $\mathrm{H}_{\mathrm{a}}$ tolak $\mathrm{H}_{\mathrm{o}}$

Jika produksi tebu rata-rata < BEP Maka terima $\mathrm{H}_{\mathrm{o}}$ tolak $\mathrm{H}_{\mathrm{a}}$

\section{HASIL DAN PEMBAHASAN \\ Karakteristik Petani}

Karakteristik merupakan sikap yang dimiliki seseorang yang menjadi suatu ciri khas orang tersebut dalam penelitian ini meliputi umur petani, pendidikan, pengalaman 
berusahatani dan jumlah tanggungan keluarga. Peranan petani dalam usahatani mencakup semua aspek sehingga menghendaki adanya keahlian dan keterampilan yang sangat tergantung kepada umur, pendidikan, pengalaman, dan tanggungan keluarga.

Suatu usahatani yang baik menghendaki agar petani yang melakukan usahatani pada batas umur yang potensial, pendidikan yang cukup, berpengalaman serta mempunyai tanggungan yang bisa membantunya. Untuk lebih jelasnya mengenai rata-rata karakteristik petani di Kecamatan Bendahara dapat dilihat pada tabel 6 berikut :

Tabel 6:Rata-rata Karakteristik Petani Tebu di Kecamatan Bendahara,2018

\begin{tabular}{|l|l|r|r|r|r|}
\hline No & \multicolumn{1}{|c|}{ Desa Sampel } & $\begin{array}{c}\text { Umur } \\
\text { (Tahun) }\end{array}$ & $\begin{array}{c}\text { Pendidikan } \\
\text { (Tahun) }\end{array}$ & \multicolumn{1}{c|}{$\begin{array}{c}\text { Pengalaman } \\
\text { (Tahun) }\end{array}$} & $\begin{array}{c}\text { Tanggungan } \\
\text { keluarga } \\
\text { (Orang) }\end{array}$ \\
\hline 1 & Marlempang & 40,6 & 8,5 & 10,3 & 4,0 \\
2 & Bandar Khalifah & 38,9 & 11,2 & 12,2 & 3,4 \\
3 & Raja & 40,8 & 10,2 & 12,7 & 3,1 \\
4 & Masjid Sungai Iyu & 44,7 & 10,8 & 15,0 & 4,5 \\
\hline \multicolumn{2}{|r|}{ Rata-rata } & 41,1 & 10,4 & 12,6 & 3,7 \\
\hline
\end{tabular}

Sumber : Data primer diolah (2018)

Berdasarkan Tabel 6 dan hasil penelitian di dapat bahwa rata-rata petani tebu di Kecamatan Bendahara berumur 41,1 tahun. Umur petani yang masih produktif menjadi salah satu fakor penting untuk meningkatkan pendapatan petani tebu didaerah tersebut.

Rata-rata pendidikan petani tebu di Kecamatan Bendahara adalah 10,4 tahun atau rata-rata Sekolah Menengah Atas (SMA). Pendidikan yang dimiliki petani sangat berpengaruh pada usahataninya. Semakin lamanya pendidikan maka semakin banyak pengetahuan yang diperoleh petani untuk diterapkan dalam usahatani yang dijalankan.

Pengalaman berusahatani di setiap petani berbeda-beda. Dari hasil penelitian ratarata pengalaman usahatani tebu di Kecamatan Bendahara adalah 12,6 tahun. Jumlah tanggungan keluarga perlu diperhatikan dalam menentukan pendapatan dalam memenuhi kebutuhannya. Semakin banyak jumlah tanggungan keluarga maka akan mendorong

Tabel 7: Rata-rata Luas Lahan Usahatani Tebu di KecamatanBendahara,2018.
\begin{tabular}{|c|l|c|}
\hline No & \multicolumn{1}{|c|}{ Desa sampel } & Luas Lahan(Ha) \\
\hline 1 & Marlempang & 0,18 \\
2 & Bandar Khalifah & 0,21 \\
3 & Raja & 0,18 \\
4 & Masjid Sungai Iyu & 0,21 \\
\hline \multicolumn{2}{|c|}{ Rata-rata } & 0,20 \\
\hline
\end{tabular}

Sumber : Data primer diolah (2018)

Dari Tabel 7 terlihat bahwa rata-rata luas lahan petani sampel di Bendahara seluas 0,20 hektar, rata-rata luas lahan terkecil terdapat di Desa Marlempang dan Desa Raja 0,18 hektar, sedangkan luas terbesar lahan terdapat di petani tebu di Kecamatan Bendahara untuk menambah pendapatannya. Dari hasil penelitian rata-rata jumlah tanggungan keluarga petani tebu di Kecamatan Bendahara adalah 4 orang.

\section{Luas Lahan Usahatani Tebu}

Luas lahan yang dimaksud dalam penelitian ini adalah luas lahan yang diusahakan petani terhadap tanaman Tebu, dimana luas lahan sangat menentukan besar kecilnya produksi yang dihasilkan. Luas lahan yang diusahakan oleh petani berbeda antara petani satu dengan yang lainnya. Hal ini tergantung dari kemampuan modal dan luas lahan petani dalam membiayai usahataninya disamping faktor keberhasilan pada periode usahatani yang lalu.

Untuk lebih jelasnya mengenai ratarata luas lahan usahatani tebudi Kecamatan Bendaharadapat dilihat pada tabel 7 berikut ini:

Desa Bandar Khalifah dan Masjid Sungai Iyu seluas 0,21 hektar. Luas lahan usahatani tebu dapat menentukan besar kecilnya pendapatan yang diterima oleh petani, semakin besar luas lahan maka semakin tinggi produksi yang 
dihasilkan maka pada usahatani pendapatan yang diterima
tebu tersebut semakin meningkat.

\section{Penggunaan Tenaga Kerja Usahatani Tebu}

Tenaga kerja yang digunakan pada usahatani tebu meliputi kegiatan pengolahan tanah, penanaman, pemupukan, sanitasi, perawatan dan pengendalian hama penyakit tanaman.dalam panen tidak di hitung karena

Tabel 8: Rata-rataPenggunaan Tenaga Kerja Usahatani Tebu di Kecamatan Bendahara, 2018.

\begin{tabular}{|c|l|c|}
\hline No & \multicolumn{1}{|c|}{ Desa } & Tenaga Kerja(HKP/UT/MT) \\
\hline 1 & Marlempang & 37,69 \\
2 & Bandar Khalifah & 41,97 \\
3 & Raja & 39,27 \\
4 & Mesjid Sungai Iyu & 45,15 \\
\hline \multicolumn{2}{|c|}{ Rata-rata } & 41,37 \\
\hline
\end{tabular}

Sumber : Data primer diolah (2018)

Tabel 8 diatas dapat dilihat bahwa rata-rata penggunaan tenaga kerja usahatani tebu di Kecamatan Bendahara yaitu sebesar 41,37 HKP/UT/MT. Rata-rata penggunaan tenaga kerja terbesar di Desa Masjid Sungai Iyu sebesar 45,15 HKP/UT/MT dan terkecil di Desa Marlempang sebesar 37,69 HKP/UT/MT.

\section{Biaya Produksi Usahatani Tebu}

Pengertian biaya produksi dalam penelitian ini adalah semua biaya yang dikeluarkan untuk menjalankan kegiatan Tabel 9: Rata-rata Penggunaan Biaya Produksi Usahatani Tebu di Kecamatan Bendahara,2018.

\begin{tabular}{|c|l|c|c|c|}
\hline \multirow{2}{*}{ No } & \multicolumn{1}{|c|}{ Desa } & \multicolumn{2}{|c|}{ Biaya(Rp/MT) } & \multirow{2}{*}{\begin{tabular}{c} 
Biaya \\
\cline { 3 - 4 }
\end{tabular}} \\
\cline { 3 - 4 } & & Biaya Tetap & Biaya Variabel & \\
\hline 1 & Marlempang & 560.656 & $2.835,667$ & $3.396,322$ \\
2 & Bandar Khalifah & 649.691 & $3.192,055$ & $3.841,745$ \\
3 & Raja & 575.952 & $2.941,457$ & $3.517,410$ \\
4 & Masjid Sungai Iyu & 676.315 & $3.391,200$ & $4.067,515$ \\
\hline \multicolumn{2}{|l|}{ Rata-rata } & 623.522 & $3.120,200$ & $3.743,722$ \\
\hline
\end{tabular}

Sumber : Data primer diolah (2018)

Tabel 9 diatas dapat dilihat rata-rata biaya produksi usahatani tebu di Kecamatan Bendahara yaitu sebesar Rp.3,743,722 /UT/MT. Rata-rata penggunaan biaya produksi tertinggi berada di Desa Masjid Sungai Iyu sebesar Rp. 4,067,515 /UT/MT, sedangkan biaya produksi terendah berada di Desa Marlempang sebesar Rp.3,396,322 /UT/MT.

\section{Produksi dan Nilai Produksi Tanaman} Tebu

Pengertian produksi dalam penelitian ini adalah produksi dalam bentuk fisik yaitu selama proses produksi berlangsung. Biaya produksi terbagi atas dua yaitu biaya tetap (Fixed Cost) yaitu biaya sewa lahan dan biaya penyusutan alat sedangkan biaya variabel (Variabel Cost) yaitu biaya upah tenaga kerja, biaya pupuk dan biaya yang di gunakan untuk membeli bibit . Untuk lebih jelasnya mengenai rata-rata penggunaan biaya produksi usahatani tebu di Kecamatan Bendahara dapat dilihat

pada tabel 9 beikut.

.Nilai produksi adalah jumlah produksi fisik dikali dengan harga hasil produksi. Besarnya nilai produksi sangat ditentukan oleh harga yang berlaku saat petani menjual hasil produksinya. Pada saat penelitian ini rata-rata harga tebu diKecamatan Bendahara adalah Rp.2,051/m. Untuk Mengetahui rata-rata produksi dan nilai produksi tanaman tebu di Kecamatan Bendahara dapat dilihat pada tabel 10 berikut. langsung dilakukan oleh pembeli (agen) Dalam menghitung besarnya pencurahan tenaga kerja yang diserap untuk setiap fase kegiatan, seluruhnya dikonversikan kedalam Hari Kerja Pria (HKP) setara dengan 1 HKP Rp 60.000 Rata-rata penggunaan tenaga kerja usahatani tebu di Kecamatan Bendahara dapat dilihat pada tabel 8 berikut.

usahatani tebu di Kecamatan Bendahara 
Tabel 10: Rata-rata Produksi dan Nilai Produksi Tanaman Tebu di Kecamatan Bendahara,2018.

\begin{tabular}{|c|l|c|c|c|}
\hline No & \multicolumn{1}{|c|}{ Desa } & $\begin{array}{c}\text { Produksi } \\
(\mathrm{m} / \mathrm{UT} / \mathrm{MT})\end{array}$ & $\begin{array}{c}\text { Harga } \\
(\mathrm{Rp} / \mathrm{m})\end{array}$ & $\begin{array}{c}\text { NilaiProduksi } \\
(\mathrm{Rp} / \mathrm{MT})\end{array}$ \\
\hline 1 & Marlempang & 5.150 & 2.017 & $10.352,500$ \\
2 & Bandar Khalifah & 6.698 & 2.055 & $13.580,636$ \\
3 & Raja & 5.387 & 2.029 & $10.831,714$ \\
4 & Masjid Sungai Iyu & 6.623 & 2.050 & $13.564,500$ \\
\hline \multicolumn{2}{|c|}{ Rata-rata } & 6.102 & 2.041 & $12.370,000$ \\
\hline
\end{tabular}

Sumber : Data primer diolah (2018)

Tabel 10 dapat dilihat bahwa rata-rata jumlah produksi tebu di Kecamatan Bendahara sebesar $6.102 \mathrm{~m} / \mathrm{UT} / \mathrm{MT}$. Rata-rata produksi tertinggi berada di Desa Bandar Khalifah sebesar $6.698 \mathrm{~m} / \mathrm{UT} / \mathrm{MT}$, sedangkan produksi terendah berada di Desa Marlempang sebesar $5.150 \mathrm{~m} / \mathrm{UT} / \mathrm{MT}$.

Sedangkan rata-rata nilai Produksi tanaman tebu di Kecamatan Bendahara yaitu sebesar Rp.12.370,000/UT/MT. Rata-rata nilai produksi tertinggi berada di Desa Masjid Sungai Iyu sebesar Rp.13.580,636/UT/MT dan

Tabel 11: Rata-rata Pendapatan Bersih Usahatani Tebu di Kecamatan Bendahara, 2018.

\begin{tabular}{|c|l|c|c|c|}
\hline No & \multicolumn{1}{|c|}{ Desa } & $\begin{array}{c}\text { Nilai Produksi } \\
(\mathrm{Rp} / \mathrm{UT} / \mathrm{MT})\end{array}$ & $\begin{array}{c}\text { Biaya Produksi } \\
(\mathrm{Rp} / \mathrm{UT} / \mathrm{MT})\end{array}$ & $\begin{array}{c}\text { Pendapatan } \\
\text { Bersih } \\
\text { (Rp/UT/MT) }\end{array}$ \\
\hline 1 & Marlempang & $10.352,500$ & $3.396,322$ & $6.956,178$ \\
2 & Bandar Khalifah & $13.580,636$ & $3.841,745$ & $9.738,891$ \\
3 & Raja & $10.831,714$ & $3.517,410$ & $7.314,305$ \\
4 & Masjid Sungai Iyu & $13.564,500$ & $4.067,515$ & $9.496,985$ \\
\hline \multicolumn{2}{|c|}{ Rata-rata } & $12.370,000$ & $3.743,722$ & $8.626,278$ \\
\hline
\end{tabular}

Sumber : Data primer diolah (2018)

Tabel 11 di atas dapat dilihat bahwa rata-rata pendapatan bersih usahatani tebu di Kecamatan Bendahara yaitu sebesar Rp.8.626,278/UT/MT. Rata-rata pendapatan bersih tertinggi berada di Desa Bandar Khalifah yaitu sebesar Rp.9,496,985/UT/MT. Sedangkan pendapatan bersih terkecil berada di Desa Marlempang sebesar Rp.6.956,178/UT/MT.

Analisis Profitabilitas Usahatani Tebu nilai produksi yang terendah berada di Desa Marlempang sebesar Rp.10.352,500/UT/MT.

\section{Pendapatan Bersih Usahatani Tebu}

Pendapatan bersih sangat dipengaruhi oleh besarnya nilai produksi dan besarnya biaya produksi usahatani tebu. Pendapatan bersih yaitu selisih antara nilai produksi dengan total biaya produksi. Rata-rata pendapatan bersih usahatani tebu di Kecamatan Bendahara dapat dilihat pada tabel 11 berikut ini: 
Dari hasil penelitian biaya tetap yang dikeluarkan dalam menjalankan usahatani tebu adalah biaya sewa lahan dan biaya penyusutan alat dengan total biaya tetap sebesar Rp.19.952.717/MT, biaya variabel yang dikeluarkan dalam mejalankan usahatani tebu adalah biaya pupuk, biaya tenaga kerja dan yang lainnya dengan total biaya variabel sebesar Rp. 99.846.400 /MT. Sedangkan Dilihat total produksi tebu di Kecamatan Tabel 13: Perbandingan Titik Impas dengan Bendahara

\begin{tabular}{|l|r|r|}
\hline \multicolumn{1}{|c|}{ Keterangan } & \multicolumn{1}{|c|}{ BEP/MT } & \multicolumn{1}{c|}{ Kondisi Aktual/MT } \\
\hline Dalam Unit (m) & 408 & 6.102 \\
Dalam Rupiah (Rp) & 831.363 & 12.370 .000 \\
& & \\
\hline
\end{tabular}

Sumber : Data primer diolah (2018)

Berdasarkan tabel 13 terlihat bahwa usahatani tebu di Kecamatan Bendahara kondisinya jauh berada di atas keadaan titik impas. Ini terlihat dari kemampuan usahatani dalam menghasilkan produksi sebesar $6.102 \mathrm{~m} / \mathrm{MT}$ sedangkan titik impas berada di titik produksi $408 \mathrm{~m} / \mathrm{MT}$. Titik impas dalam rupiah berada di Rp.831.363 /MT. Sedangkan Kondisi Aktual usahatani memperoleh jauh lebih tinggi dari titik impasnya yaitu sebesar Rp.12.370.000/MT.

Hasil analisis Profitabilitas usahatani di Kecamatan Bendahara Kabupaten Aceh Tamiang diperoleh keuntungan sebesar $\mathrm{Rp}$ 8.626.278.- dan penjualan sebesar Rp.12.370.000-, sehingga nilai Net Profit Margin (NPM) diperoleh sebesar $69 \%$ yang bearti nilai NPM lebih besar dari pada 5\%, yaitu keuntungan yang diperoleh dari hasil penjualan usahatani $69 \%$ lebih besar dari pada biaya yang dikeluarkan. Berdasarkan perhitungan NPM yang diterima bahwa usahatani tebu efisien untuk di laksanakan

Untuk Return Of Invesment (ROI) diperoleh sebesar $230 \%$ bearti nilai ROI yang diperoleh lebih dari $50 \%$ bearti tingkat efesiensi penggunaan modal melebihi kriteria yang diberikan yang artinya setiap pengeluaran $\mathrm{Rp} 1$ maka keuntungan yang diperoleh sebesar $\mathrm{Rp} 230$ atau 230\% bila dibandingkan dengan biaya produksi.

\section{KESIMPULAN DAN SARAN Kesimpulan}

1. Rata-rata petani tebu didaerah penelitian berumur 41,1 tahun dan pengalaman dalam usahatani tebu rata-rata 12,6
Bendahara sebesar $195.270 \mathrm{~m} / \mathrm{MT}$ dengan harga rata-rata Rp.2.041.

Titik impas atau BEP (Break Event Point) adalah titik pulang pokok, atau tingkat operasi/produksi dimana perusahaan tidak mengalami kerugian, namun juga tidak mendapat laba (Noor, 2013:200). Adapun perbandingan titik impas dengan kondisi aktual usahatani tebu di Kecamatan Bendahara dapat dilihat lebih jelas pada tabel 13 berikut :
Kondisi Aktual Usahatani Tebu di Kecamatan

tahun, serta pendidikanya 10,4 tahun dengan jumlah tanggungan keluarga rata-rata 4 orang.

2. Rata-rata luas lahan usahatani tebu didaerah penelitian adalah $0,20 \mathrm{Ha}$. Rata-rata penggunaan tenaga kerja usahatani tebu di Kecamatan Bendahara yaitu sebesar41,57 HKP/MT. Rata-rata biaya produksi usahatani tebu di Kecamatan Bendahara yaitu sebesar Rp.3,365,513/ MT. Rata-rata produksi yaitu sebesar 6,102 m/MT. Rata-rata nilai produksi usahatani tebu di Kecamatan Bendahara yaitu sebesar Rp.12,370,000/MT dan rata-rata pendapatan bersih usahatani tebu di Kecamatan Bendahara yaitu sebesar Rp.9,004,488/MT

3. Dari hasil analisis BEP untuk mencapai keadaan impas, usahatani tebu di Kecamatan Bendahara harus berproduksi sebesar $408 \mathrm{~m} / \mathrm{MT}$ dengan total penerimaan Rp.831.363 /MT

4. Hasil analisis profitabilitas diperoleh nilai NPM (Net Profit Margin )sebesar $69 \%$ yang menunjukkan bahwa penjualan relatif lebih tinggi $69 \%$ dari pada pengeluaran dan nilai ROI (Return Of Invesment) $230 \%$, artinya setiap pengeluaran $\mathrm{Rp} 1$ maka mendapatkan keuntungan sebesar Rp 2,30 atau 230\% bila dibandingkan dengan biaya produksi.

\section{Saran}

1. Diharapkan petani tebu di Kecamatan Bendahara dapat mempertahankan atau meningkatkan produksi, pada usahatani 
tebu sehingga dapat diperoleh pendapatan bersih yang lebih tinggi lagi.

2. Diharapkan petani tebu di Kecamatan Bendahara untuk dapat menerapkan penggunaan pupuk sesuai anjuran dari dinas pertanian/perkebunan setempat agar pertumbuhan dan produksi tanaman tebu meningkat.

3. Dalam upaya peningkatan pendapatan, petani diharapkan dapat dengan usaha menambah areal lahan garapan agar memperoleh keuntungan yang lebih tinggi.

\section{Daftar Pustaka}

Agus R Sartono, 2008, Manajemen Keuangan Teoridan Aplikasi. Edisi 4 BPFE, Yogyakarta

Ahmad, 2007.Budidaya Tebu, Azka press, Jakarta

Badan Penyuluhan Pertanian Kecamatan Bendahara, 2016. Laporan Akhir Tahun BPP Bendahara, Aceh Tamiang

Badan Pusat Statistik 2016, Aceh Tamiang Dalam Angka, Badan Pusat Statistik Aceh Tamiang

Daniel, 2002, Pengantar Ekonomi Pertanian, Bumi Aksara, Jakarta

Gustiana, 2004, Analisis Pendapatan Usahatani Untuk Produk Pertanian, Salemba Empat, Jakarta

Imam Seoharto, 2001, Studi Kelayakan Proyek Industri, Erlangga, Jakarta

Kasmir dan Jakfar, 2009, Studi Kelayakan Bisnis ,Kencana, Jakarta

Ken Suratiah, 2009. Ilmu Usaha Tani. Penebar Swadaya, Jakarta

M. Syakir, 2010, Budidaya dan Pasca Panen Tebu, ESKA Media, Bogor

Mubyarto.2003. Pengantar Ekonomi Pertanian. Jakarta , LP3ES.

Mulyadi, 2002, Akutansi Biaya, Aditya Media.Yogyakarta.

Mulyadi. 2001. Sistem Akuntansi. Jakarta : Salemba Empat

Murbyanto, 1998 Metodelogi Penelitian Ekonomi, Yayasan Agronomika, Yogyakarta.

Nazir, Moh, 2005. Metode Penelitian. Ghalia Indonesia, Jakarta.

Petronila, Thio Anatasya Muklasin, 2003"Pengaruh Profitabilitas Perusahaan Terhadap Ketepatan
Waktu Pelaporan Keuangan Dengan Opini Audit Sebagai Moderating Variabel" Jurnal Ekonomi dan Bisnis Universitas Khatolik Indonesia, Atmajaya, Jakarta.

Rahim dan Diah, 2008.Ekonomi Pertanian, Penebar Swadaya. Jakarta

Rezeki Handayani, 2013 Analisis Profitabilitas Usahatani Kelapa (Cocos Nucifera L) Di Kecamatan Birem Bayeun, Kabupaten Aceh Timur.

Sudarman A.2004. Teori Ekonomi Mikro. BPFE UGM. Yogyakarta

Soekamto, 2001, Upaya Meninggkatkan Produksi ,Penebar Swadaya, Jakarta

Soemarso, 2002, Akutansi Suatu Pengantar, Rineka Cipta, Jakarta.

Sugiyono, 2008. Metode Penelitian Pendidikan (Pendekatan Kuantitatif, Kualitatif dan R,D) Penebar Alfabeta, Bandung.

Sukirno, S. 2005, Pengantar Teori Mikro Ekonomi, Bima Grafika, Jakarta.

Sutardjo, 2009, Budidaya Tanaman Tebu, Penebar Swadaya, Jakarta.

Suwarto, 2010.Budidaya Tanaman

Perkebunan Unggulan, Penebar Swadaya, Jakarta 